\title{
Integrity Among Civil Servant in Malaysian Government Office
}

\author{
Afidah Yusoff ${ }^{1}$, Samsudin Wahab ${ }^{2}$, Mawarni Abdul Rashid ${ }^{3}$, Mohd Nashriq Samsuddin ${ }^{4}$ \\ \{ afidah.yusoff@jpnpp.edu.my ${ }^{1}$, fimago66@gmail.com ${ }^{2}$, ladylikeone@ gmail.com ${ }^{3}$, \\ nashriqsamsuddin@yahoo.com ${ }^{4}$ \} \\ 1,2,3,4 Universiti Teknologi MARA, Pulau Pinang, 13500 Bukit Mertajam, Pulau Pinang
}

\begin{abstract}
High quality civil servants are an important asset to success organizations and countries. The nature of trust, transparency, responsibility and serving in the public interest is the essence of integrity and ethical terms. In other words, integrity and ethics in work and organization involve good actions done in the work and all of these have a strong connection with religious teachings and responsibilities as human beings. The lack of integrity among civil servants will result in administrative malfunction and corruption misconduct within the organization. Hence, the practice and understanding of integrity and ethics is essential implemented. Integrity and a good sense of identity need to be in every human being. This is because lack of integrity in an organization can cause many problems such as wastages, injuries, less productivity, illness and corruption. From integrity in workplace, employers, employees and leaders can get benefit in workplace. Every individual can work in harmony and enthusiasm. This indirectly increases productivity and fosters the spirit of mutual cooperation and integrity amongst one another.
\end{abstract}

Keywords: civil servants, ethics, integrity

\section{Introduction}

Often, we hear people mention integrity and it can be said that every day this phrase comes from the lips of the speaker or at least we will meet this word while reading newspapers, magazines, books and other reading materials. Even everywhere are often talked about the lack of integrity among the public, workers in the public sector, private sector or among politicians.

What does it mean or can be understood with integrity? Does this term reflect the nature or is closely related to the personality of a person? According to the bilingual dictionaries of Dewan Bahasa dan Pustaka (DBP) 1985 [1] is "honesty and sincerity", perfection, 'wholeness'. This means integrity is the "identity" nature that also includes sincerity, openness, transparency, trustworthiness, truth, adherence to principles, not easy to influence, trustworthy, capable of speaking and others.

Integrity, on the other hand, is a virtue (good value) derived from the Latin word integer [2]. Referring to Oxford Dictionary, integrity relates to honesty and goodness, wholeness and unity. It is an ethical value among many other universally accepted virtues. According to [3], former President of Malaysian Institute of Integrity (Integriti Malaysia), "Integrity is the quality of being honest and upright. It is about individual and organizational characteristics which are perfect based on noble values such as honest, truthful, trustworthy, accountable, transparent, efficient and wise. Individual integrity is the harmony between what he/she says and does. Actions are in accordance with moral and ethical principles as well as laws and 
regulations and do not go against public interest. They also reflect promptness, correctness and quality."

According to [4], integrity is defined as a stage or balance state between personal space, autonomy and individual values. Researcher in [5] defines integrity as a person's internal consistency and coherence with his statements and actions. Integrity is an important concept in ethical reasoning [6]. Integrity is also closely linked to the establishment and strengthening of good ethics.

Government agencies are constantly faced with various forms of threats from within or outside the environment and these threats can affect the performance, productivity and future of an organization. Most threats to the organization come from individuals within the organization itself and thus involve other individuals who are damaging to the identity of the government organization. These threats usually have a close relationship with ethical and integrity issues. Corruption, abuse of power within an organization can occur if ethics and integrity are ignored.

\subsection{Integrity among civil servants}

The integrity of civil servants is to implement the trust and power given to the public interest and not to abuse such power for the benefit of themselves, their families, relatives or relatives. In the event of a conflict of interest, priority should be given to the public interest. The following are among the civil servants with integrity that confirm to:

Peratuaran-Peraturan Pegawai Awam (Kelakuan dan Tatatertib) 1993.

1. Come early to the office or on time.

2. Fulfill customer needs with friendly and prudent

3. Not misuse of office equipment and facilities.

4. Eat and drink only at lunch break.

5. Do not go out of office without permission.

6. Conduct the task in earnest and diligent.

7. Do not accept / request bribe from customers.

8. Submit the claim honestly.

9. Perform work quickly, accurately and with integrity.

10. Use office vehicles for official business only.

Integrity is very closely related to excellence. A civil servant who performs his duties with integrity will achieve excellence. When a public servant is integral in performing his duties, he / she will produce quality tasks, tasks can be implemented efficiently and quickly and the services rendered to the customer are well-executed and polite. Integrity is doing the right thing when no one is watching. It is a choice between what is convenient and what is right. Researcher in [7] classified integrity into three categories. They are personal integrity, moral integrity, and organizational integrity.

Researcher in [8] mentioned that personal integrity consists of wholeness; consistency of words; consistency in adversity; being true to oneself; and also moral or ethical behavior. Individual integrity is the full alignment in what a person thinks, says and does [9]. Personal integrity is the quality of being truthful and honest with yourself and others, of intentionally aligning personal behaviors and actions to be congruently aligned with our own Personal Value System, moral principles, and ethics. It generally requires personal choice and commitment to align ourselves to stay consistent with personal values and ethical standards, so that when we speak, we mean what we say.

Ethical integrity leadership is important for the economic prosperity of an organization [10]. Researcher in [11] said that integrity is essential in securing the goodwill and best 
efforts of employees [12]. Organizational integrity refers to the ethical integrity of the individual actors, the ethical quality of their interaction as well as that of the dominating norms, activities, decision making procedures and results within a given organization.

Integrity at the corporate level refers to the culture, policies, and leadership philosophy. Unethical behavior can be overcome by learning about integrity matters. For example, by providing education to raise awareness about importance of integrity, including accounting, economic, social and environmental systems, are included in corporate governance. The neglect of integrity can affect the overall performance of an organization.

\subsection{What contributes to lack of integrity?}

What does it mean to lack integrity? While a person who acts dishonestly is obviously also acting without integrity, a person may lack integrity without being dishonest. People can lose integrity anytime they are asked a difficult question or are presented with a situation requiring moral action. Most people will shy away from confrontation, and choose denial or willing blindness, rather than admit they are wrong, or things may not be what they believed them to be. When confronted with making a moral choice, most act out of self-interest even though rules and values that they profess to live by would suggest that they would want to be supportive of others and live by a higher moral code. People can lose their integrity when they refuse to admit they are wrong, or when they lie or fail to tell the truth when they discover what the truth is.

The word 'integrity' is one of the most frequently used terms as soon as the government announces that some UPSR 2014 question papers have been cut off and the candidates are directed to re-take the paper. This incredibly disastrous and embarrassing event has had a very different impact on our children who are still in school. At this point, they should learn about "effort" and "earnestness" will produce a proud result, but now they are beginning to be admired by real world reality full of deceit and dishonesty. This indirectly exposes them to the purpose of integrity and educators should now try to restore the confidence of these children that integrity exists in society and every good will be rewarded with kindness as well.

The absence of these good traits in individuals and societies can lead to incorrect criminal and moral behavior for example corruption, breach of trust, steal, oppress, cheats etc. Therefore, it is not wrong if we say that the leak in this UPSR question paper is related to the lack of integrity among our society in general and among its special civil servants.

\subsection{Broken Trust and Corruption}

Generally when we talk about integrity, we will be more focused on cases of breach of trust and corruption. It should be noted that the scope of integrity is broader. Work culture practices also demand integrity. Integrity in timeliness, integrity in conveying information, integrity in providing best service, integrity in relation to department heads, colleagues and support staff. However, the successful measurement of the implementation of this integrated culture can be seen with the reduction of corruption cases and breach of trust.

\subsection{MACC: Malaysian Anti-Corruption Commission}

That is why the government has created a special body to combat this problem and the body is the Malaysian Anti-Corruption Commission (MACC). The existence of the MACC is in line with the aspirations of the people who want a more transparent, transparent and professional anti-corruption entity. The MACC is set up under the Malaysian Anti-Corruption 
Commission (MACC) Act 2009 (Act 694) and has since been established to have various investigations and arrests to curb corruption and criminal breach of trust.

Table 1. Number of Arrested Civil Servants 2018

\begin{tabular}{|c|c|c|c|c|}
\hline & $\begin{array}{c}\text { Top } \\
\text { Management }\end{array}$ & $\begin{array}{c}\text { Professional and } \\
\text { Management }\end{array}$ & Support Staff & Total \\
\hline January & 0 & 14 & 13 & $\mathbf{2 7}$ \\
\hline February & 0 & 5 & 16 & $\mathbf{2 1}$ \\
\hline March & 0 & 1 & 14 & $\mathbf{1 5}$ \\
\hline April & 0 & 38 & 26 & $\mathbf{6 4}$ \\
\hline May & 0 & 5 & 2 & $\mathbf{7}$ \\
\hline June & 0 & 9 & 3 & $\mathbf{1 2}$ \\
\hline July & 0 & 7 & 37 & $\mathbf{4 4}$ \\
\hline August & 2 & 14 & 48 & $\mathbf{6 4}$ \\
\hline September & 0 & 17 & 51 & $\mathbf{6 8}$ \\
\hline October & 10 & 17 & 49 & $\mathbf{7 6}$ \\
\hline November & 1 & 14 & 13 & $\mathbf{2 8}$ \\
\hline Disember & 0 & 1 & 1 & $\mathbf{2}$ \\
\hline Total & $\mathbf{1 3}$ & $\mathbf{1 4 2}$ & $\mathbf{2 7 3}$ & $\mathbf{4 2 8}$ \\
\hline
\end{tabular}

Source: https://www.sprm.gov.my/

Corruption is integrity destroyer and the increasing number of civil servant arrests so much worrying. Above all integrity issues, corruption is widely discussed. MACC statistics show the arrest of civil servants is high. Corruption can result in damage to buildings, bridges, or roads. Corruption also results in problematic social environment and the economy becomes weak. Less investment will lead to less job opportunities. Public funds will reduce for better education, infrastructure and healthcare. (Kimeu,2014) mentioned that cost of corruption more than $5 \%$ of global GDP with over US\$1 trillion paid in bribes each year.

Despite the growing concern of many parties on the decline in integrity among civil servants, the Malaysian government has introduced various initiative to create awareness about the importance of integrity. The Malaysian government has also established various mechanisms to monitor the misconduct associated with civil servants. Most of these efforts focus on improving service delivery to the public and maintaining the interests of its stakeholders.

\section{Efforts Taken by Malaysian Government to Improve Integrity Among Civil Servant}

Enforcement Agency Integrity Commission is a Federal Statutory Body established by an Act of Parliament, under Section 3 of Enforcement Agency Integrity Commission Act 2009 [Act 700] which was gazette on 3 September 2009. The Act 700 was enforced on 1 April 2011. This Act replaces the Independent Police Complaints and Misconduct Commission Bill 2005. The establishment of the Commission is in line with the Government's aim to inculcate and enhance integrity among enforcement officers and law enforcement agencies thus strengthening public confidence in them.

Since the Act came into force, the Commission has begun to carry out functions as provided in section 4 of Act 700 . The main function of this Commission is to receive 
complaints of misconduct from the public against enforcement officers or law enforcement agencies in general and investigate and hold a hearing on the complaints received.

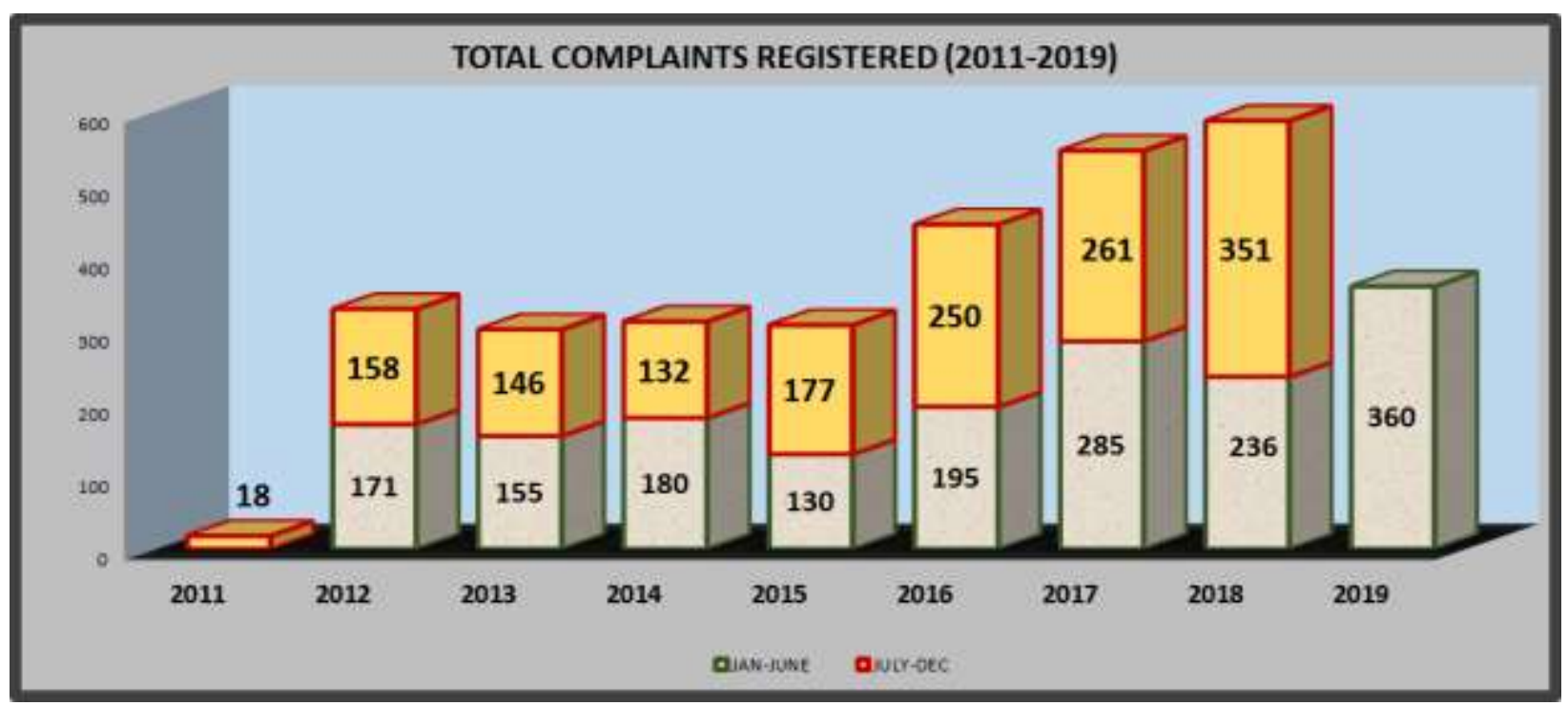

Fig 1. Total Complaints Registered (2011-2019)

Source: http://www.eaic.gov.my

Based on the above graph issued by the Enforcement Agency Integrity Commission shows an increase in complaints from year to year. Half year low in 2019, statistics showed a very high increase compared to the first half of 2018. In January-June 2018, the number of complaints was 236 compared to January-June 2019 complaints of 360. This shows more people watching the behavior of civil servants and more people daring to lodge complaints against civil servants. this is because, many channels have now been available for the public to make a complaint.

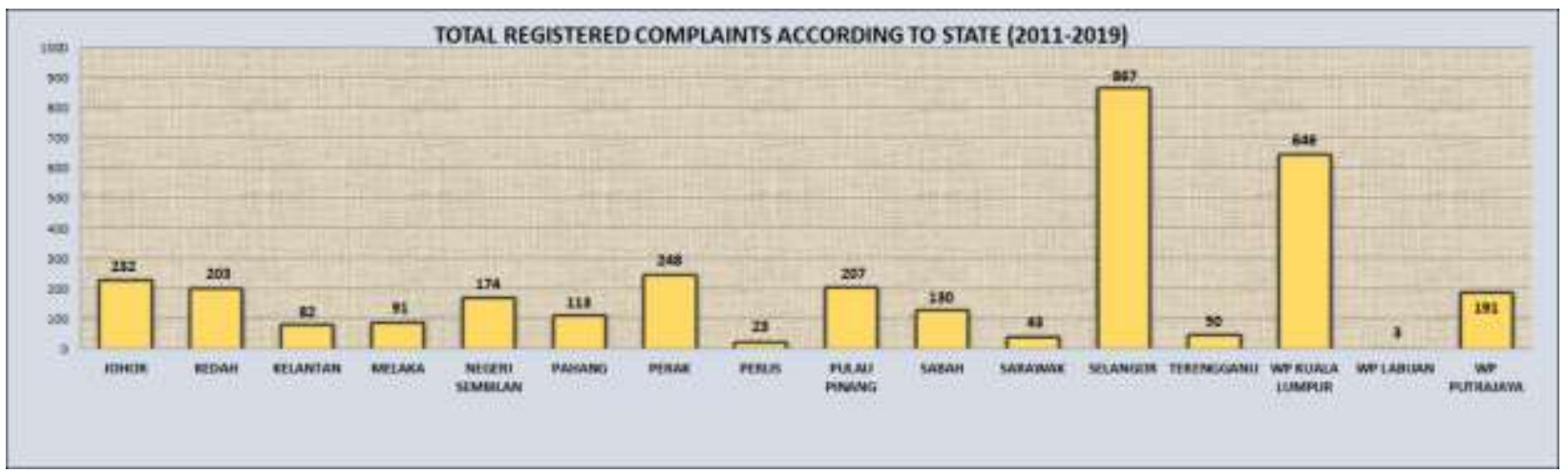

Fig 2. Total Registered Complaints According To State (2011-2019)

Source: http://www.eaic.gov.my 
This graph shows the comparisons of the number of state-based complainants from 2011 to June 2019. Selangor received the highest number of complaints of 867 complaints and followed by the Federal Territory of Kuala Lumpur with 646 complaints

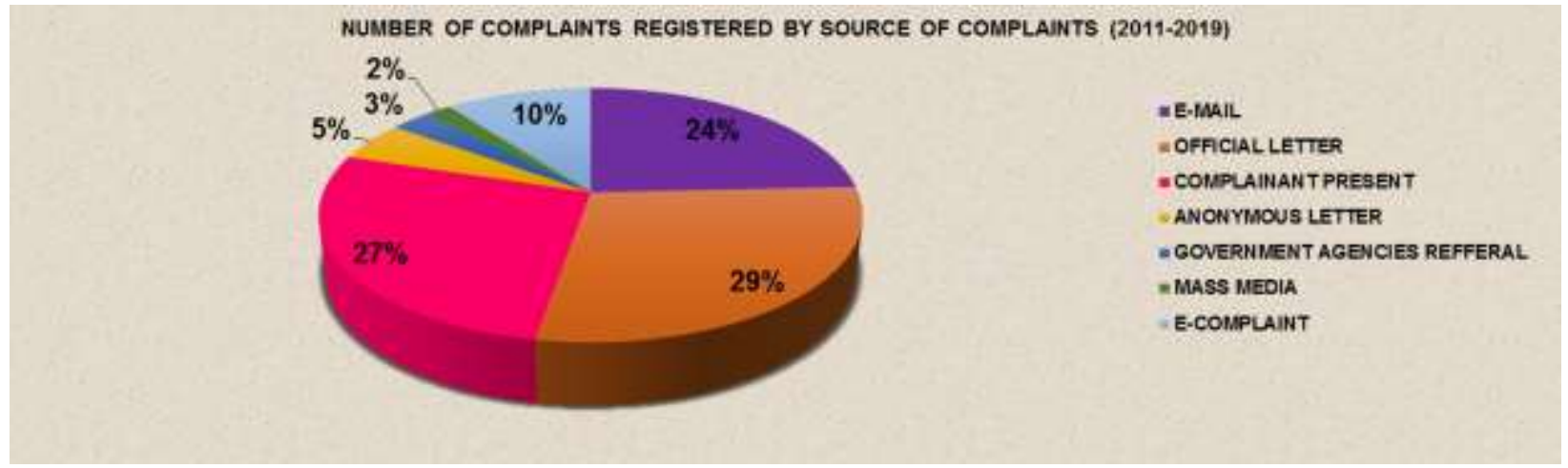

Fig 3. Number Of Complaints Registered By Source Of Complaints (2011-2019) As at $14 / 06 / 2019$

Source: http://www.eaic.gov.my

The pie chart above shows the percentage of people submitting complaints through multiple channels.

\section{Conclusion}

Integrity implies superior quality that exists as a whole and solidly in individuals and organizations. Integrity is closely related to ethics and ethical based on daily action. Work culture refers to the values, beliefs, attitudes, beliefs and attitudes of workers towards their work. In the context of integrity it is not only focused on corruption issues, but it is also a bigger concept as it involves also a culture of work that demands integrity practices such as integrity in timeliness, integrity in information delivery, integrity in providing best service, integrity in relation to heads of departments, colleagues, communities and support staff.

Integrity in services should be demonstrated by civil servants through the exercise of the trust and authority entrusted to them in the public interest. If a non-integrity act is left uninterrupted, it will eliminate the trust of the society and affect the image of workers, the country and disable strong corporate entities. It is understandable that integrity among civil servants are important to nurture in order to create a competitive and developed Malaysian nation.

In conclusion it can be concluded that the ethics exist from within an individual with the existence of complete discipline and strength. In the political aspect, noble values are the prerequisites to the integrity of a government's machinery of machinery, the perception of the people in terms of transparency and the benchmark on the trust of an individual. Hence, the effort to strengthen the integrity and best governance requires the commitment of all parties in the civil service namely the officers, staff and organizations themselves by following all the rules and best practices. Islam encourages its people to work with trustworthiness, honesty, goodwill, affection and warmth between employers and employees and between employers and employees in all matters of service as long as they do not violate Islamic law to form successful and devout communities. 
Acknowledgement. The authors would like to highlight the enormous appreciation offered by Universiti Teknologi MARA Cawangan Pulau Pinang.

\section{References}

[1] Kamus Dewan, Kualiti. Dewan Bahasa dan Pustaka, vol. Edisi Keem. 2010.

[2] P. Stanwick and S. D. Stanwick, Understanding business ethics. Sage, 2013.

[3] M. T. Salleh, Enhancing Integrity in the Public Service. 2007.

[4] E. D. Pellegrino, "Patient and physician autonomy: conflicting rights and obligations in the physician-patient relationship.," J. Contemp. Health Law Policy, 1994.

[5] A. W. Musschenga, "Education for Moral Integrity,” J. Philos. Educ., 2001.

[6] I. Widäng and B. Fridlund, "Self-respect, dignity and confidence: Conceptions of integrity among male patients," J. Adv. Nurs., 2003.

[7] N. T. Rosa, "Integrity: a systems theory classification," J. Manag. Hist., vol. 13, no. 1, pp. 74-93, Jan. 2007.

[8] M. E. Palanski and F. J. Yammarino, "Integrity and Leadership:. Clearing the Conceptual Confusion," Eur. Manag. J., 2007.

[9] Linda Fisher Thornton, "What Is Organizational Integrity?," 2016. [Online]. Available: https://www.linkedin.com/pulse/what-organizational-integrity-linda-fisher-thornton.

[10] J. C. Thoms, "Ethical integrity in leadership and organizational moral culture," Leadership. 2008.

[11] A. Morrison, "Integrity and global leadership," J. Bus. Ethics, 2001.

[12] G. Palazzo, "Organizational Integrity — Understanding the Dimensions of Ethical and Unethical Behavior in Corporations," in Corporate Ethics and Corporate Governance, 2007. 